\title{
As Ciências da Terra e a mundialização das sociedades
}

\author{
UMBERTO G. CORDANI
}

$\mathrm{P}$ RETENDO EXPOR, nesta oportunidade, algumas idéias do que entendo ser o futuro papel das ciências da Terra, levando em conta a crescente mundialização das sociedades. Faço-o com os devidos cuidados, conhecedor de minhas deficiências de formação, especialmente nas ciências sociais e humanas, com o objetivo de oferecer alguns temas para a reflexão dos colegas pesquisadores e profissionais das geociências e das ciências da natureza em geral.

O termo mundialização é aqui empregado praticamente como sinônimo de globalização, observando ser esta encarada como fenômeno que basicamente afeta a economia, embora considere também aspectos sociais e culturais. Falo em sociedades, ao invés de considerar um cenário de sociedade global, por acreditar na manutenção dos valores culturais tradicionais, que caracterizam os povos e as nações do mundo, apesar de sua inserção no panorama de interpenetrações sócio-econômicas e culturais, os quais marcam o processo de mundialização na grande aldeia global que já nos abriga.

\section{Desenvolvimento sustentável}

Estudos sobre desenvolvimento iniciaram-se por volta dos anos 50, quando muitos territórios coloniais tornaram-se independentes. A ONU denominou a década de 60 como a Primeira Década das Nações Unidas para o Desenvolvimento, imaginando que através da cooperação internacional, proporcionando crescimento econômico pela transferência de tecnologia, experiência e fundos monetários, os problemas dos países subdesenvolvidos pudessem ser rapidamente resolvidos. Tal otimismo dissolveu-se poucos anos mais tarde, quando se verificou o crescimento da pobreza e das desigualdades, no assim chamado Terceiro Mundo. Mudou então a percepção de desenvolvimento, e durante a Terceira Década das Nações Unidas para o Desenvolvimento (os anos 80), buscaram-se estratégias de distribuição, procurando assegurar que os benefícios do possível crescimento econômico não ficassem restritos a pequenas minorias das populações envolvidas.

A questão ambiental assumiu proporções de relevância apenas nos anos 60, época em que muitos grupos de ação, quase sempre com suporte explícito 
de órgãos da mídia, induziram a articulação de uma filosofia coerente, e de uma terminologia específica com relação ao ambiente. De início, muitos países em desenvolvimento, inclusive o Brasil, consideraram inviável incluir a conservação ambiental em seus respectivos planos nacionais, visto que certos graus de poluição e deterioração ambiental eram considerados conseqüências inevitáveis do desenvolvimento industrial, e isso ficou muito claro na Conferência das Nações Unidas sobre o Ambiente Humano, realizada em Estocolmo, em 1972. Por outro lado, na mesma conferência, foi reconhecido o inter-relacionamento entre os dois conceitos, ocasião em que as idéias de degradação ambiental foram ampliadas para incluir aqueles efeitos causados pela falta de desenvolvimento. Em Estocolmo foram cunhadas as idéias de poluição da pobreza e ecodesenvolvimento.

Durante os anos 80, as Nações Unidas encarregaram uma comissão internacional de alto nível, presidida por Mrs. Go Brundtland, Primeira Ministra da Noruega, de efetuar amplo estudo a respeito dos problemas globais de ambiente e desenvolvimento. A comissão apresentou o Relatório Brundtland (1987), no qual foi caracterizado o conceito de desenvolvimento sustentável. O relatório teve ampla repercussão mundial, e estimulou a ONU a organizar a maior reunião de chefes de Estado da história, em 1992, no Rio de Janeiro, a Conferência das Nações Unidas sobre Ambiente e Desenvolvimento, UnCED-92, ou Rio-92. A meu ver, tendo participado dela como observador, através do ICSU - Conselho Internacional de Uniões Científicas, o maior valor do evento foi o de ter despertado, de maneira irreversível, a consciência mundial para os problemas globais. A questão ambiental, e sua relação com o desenvolvimento, tornou-se assunto familiar, é discutida em salas de aula do mundo todo e não pode mais ser ignorada por qualquer governo, nem por qualquer pessoa envolvida com políticas públicas.

Desenvolvimento sustentável foi então definido no mencionado Relatório Brundtland. O que pretende é alcançar uma situação ideal de justiça social, para a humanidade, na qual o desenvolvimento sócio-econômico, em bases eqüitativas, estaria em harmonia com os sistemas de suporte da vida na Terra. Em tal situação, ocorreria certa melhoria na qualidade de vida das populações, cujas necessidades (e alguns dos desejos) da presente geração estariam satisfeitas sem prejuízos para as gerações futuras. O paradigma do desenvolvimento sustentável inclui, necessariamente, equilíbrio de desenvolvimento sócio-econômico, preservação e conservação do ambiente, e também controle dos recursos naturais essenciais, como água, energia e alimentos.

Os conhecimentos científico e tecnológico necessários para a busca de tal situação ideal já se encontram em grande parte disponíveis. Por exemplo, já são conhecidos muitos tipos de tecnologias limpas com relação ao ambiente, muitos processos de reciclagem de rejeitos industriais, muitas técnicas de agricultura regenerativa. Ainda não se encontra, entretanto, resolvido o problema da disponibilidade de fontes renováveis de energia, em quantidade compatível com as 
necessidades futuras, e estamos longe de uma solução final para o problema maior, qual seja, o de conter o crescimento populacional, especialmente nos países em desenvolvimento.

Foram necessárias inúmeras gerações de Homo sapiens, talvez cinqüenta ou cem mil gerações, para que a população mundial da Terra atingisse a situação atual de quase cinco bilhões e meio de pessoas. E apesar de todos os avisos, desde Malthus, passando pelo Clube de Roma, e seus limites do crescimento, até a última conferência das Nações Unidas, realizada no Cairo, parece inevitável que a população mundial duplicará nos próximos 50 anos (United Nations, 1991). O cenário proposto em muitos dos estudos da ONU é o de estabilização populacional em patamar da ordem de 10-11 bilhões em meados do século XXI. Pessoalmente, entendo que o problema de evitar a ameaça de uma explosão populacional descontrolada é de longe o mais crucial, e a ele foi dada importância menor nas discussões da UNCED-92. Por outro lado, o problema foi ampla e especificamente discutido na recente Conferência das Nações Unidas sobre População e Desenvolvimento, no Cairo, já referida. Espera-se agora que apareçam as ações resultantes, por parte das organizações internacionais envolvidas, ou pelos governos interessados.

A meu ver, o alcance da estabilidade populacional (crescimento zero) somente será possível à medida em que forem sendo atingidos os padrões de desenvolvimento sócio-econômico com justiça social e com erradicação da pobreza, bem como os níveis de educação e de esclarecimento desejáveis, em especial nos países do Terceiro Mundo. Nesta altura, cabe a nós apenas a esperança de que tal cenário ideal possa de fato ser alcançado em meados do próximo século, pois quaisquer outros cenários possíveis são no mínimo assustadores.

O crescimento populacional para um patamar de 10-11 bilhões de pessoas leva a indagar sobre a sustentabilidade do planeta e coloca em evidência a contradição implícita do desenvolvimento sustentável, como foi caracterizado. Com efeito, a Terra é finita e os sistemas de suporte da vida são limitados. Os recursos disponíveis no planeta seriam suficientes para garantir uma vida decente para tanta gente? $\mathrm{Na}$ expressão desenvolvimento sustentável, a sustentabilidade é utilizada meramente como adjetivo qualificativo e não, como entendo que deva ser, como conceito fundamental e termo de referência básico. Sustentabilidade não pode ser definida em termos econômicos, ou seja, nosso ecossistema global não pode ser caracterizado no sentido de adequar-se às nossas necessidades e desejos. Necessariamente, estes últimos é que têm de ser definidos a partir das limitações impostas pelo sistema.

A Ciência e a Tecnologia têm responsabilidade essencial para o futuro da humanidade: a de fornecer instrumentos para modificar os padrões atuais de desenvolvimento, tendo em vista que estes, de modo geral, possuem como paradigma a sociedade dos países do Primeiro Mundo, com seu desperdício e 
consumo exagerado de recursos naturais e energéticos. Nossos padrões existenciais atuais nãa são sustentápeis, e nossas atitudes sócio-econômicas são perversas, se observarmos as diferenças de qualidade de vida entre os países desenvolvidos e aqueles em desenvolvimento, que continuam aumentando. Parece evidente que acordos políticos e medidas puramente econômicas têm pouca chance de sucesso neste mundo egoísta, em que nacionalismos, corporativismos, regionalismos, xenofobias acabam fazendo prevalecer interesses de minorias acima dos interesses públicos, comunitários, globais. Estamos vivendo numa época muito especial da história das civilizações, quando nosso planeta está se aproximando de uma saturação. A meu ver, uma sociedade global ideal, sustentável, apenas poderá ser alcançada se houver uma espécie de acordo social, baseado em princípios éticos, de solidariedade humana, intra e intergerações, incluindo-se aqui o planejamento cuidadoso para o bem-estar da humanidade, a longo prazo, para os próximos séculos.

\section{O papel das ciências da Terra numa sociedade sustentável}

Ciências da Terra, neste ensaio, incluem tudo o que diz respeito ao conhecimento e ao manejo tecnológico dos aspectos inerentes ao nosso planeta, seus processos naturais e sua dinâmica, especialmente a que se manifesta em sua superfície. Incluem os campos de atuação da Geologia, da Geofísica, da Meteorologia, da Oceanografia, da Ecologia, bem como muitos aspectos técnicos inerentes às Engenharias, e também muitos que tangenciam as Ciências Humanas, através de sua relação estreita com a Geografia.

As interconexões são complexas e as atividades interdisciplinares muito comuns. De modo geral, os cientistas e os profissionais do presente e do futuro terão de adaptar-se de forma crescente para o eqüacionamento correto de problemas globais, o que envolve a atuação de especialidades distintas. Os pesquisadores atuais foram preparados para desenvolver ao máximo suas experiências em campos de atuação muito reduzidos. Esta tendência terá de ser revertida e, ao mesmo tempo, os cientistas também deverão desenvolver a humildade necessária para reconhecer que quaisquer experiências individuais poderão não ser suficientes para encontrar respostas satisfatórias a problemas globais.

Além dos aspectos básicos de todos os campos de ciência mencionados e que serão desenvolvidos de qualquer forma na única dependência da curiosidade humana, a meu ver existem seis missões principais inerentes às Ciências da Terra, a serviço de uma sociedade sustentável.

\section{Monitoramento contínuo dos processos do Sistema Terra}

Nosso planeta apresenta uma dinâmica natural intensa, com flutuações em qualquer escala de tempo. Cabe aos geocientistas o seu monitoramento, através 
de observações regionais e globais coordenadas, o que já está sendo realizado, por exemplo em redes internacionais, como as estações da Organização Mundial de Meteorologia ou em observatórios sismológicos do Sistema Mundial de Observações Sísmicas. São de rotina, também, observações por sensoriamento remoto de fenômenos atmosféricos, de regimes hidrológicos, de padrões de vegetação etc. Como exemplo prático de monitoramento global, citam-se observações desta natureza que permitiram aos cientistas alertar a respeito de problemas que poderão ocorrer em conseqüência do aquecimento global do planeta e do derretimento de parte das calotas polares.

\section{Busca, gerenciamento e fornecimento de recursos minerais}

Estas sempre foram algumas das missões principais das Geociências. A economia mineral funciona com mecanismos complexos, nos quais determinadas formas de apresentação de minérios são definidas como mercadorias padronizadas (commodities) e os empreendimentos mineiros envolvem cadeias de rentabilidade que têm de levar em conta combinações de equipamentos, teores dos minérios, operações de beneficiamento e de venda, bem como a duração das reservas em cada nível de tecnologia empregado. Nos anos 80, a mineração foi afetada por séria recessão, que ainda persiste, com grande queda dos preços dos minérios. As causas são diversas, entre as quais podem ser citadas: o crescimento da reciclagem industrial e a substituição de metais por novos materiais, o que provocou queda na demanda; o aumento na oferta de bens minerais já disponíveis pelo término dos estoques estratégicos do governo norte-americano, com o fim da Guerra- Fria, e as vendas de grande quantidade de material pelos países do Leste europeu, com o objetivo de obtenção de moeda forte. Ao mesmo tempo, já no presente, e cada vez mais no futuro, a exploração dos recursos minerais disponíveis deve e deverá levar em conta os custos ambientais, que serão parte cada vez mais importante das equações custo-benefício das operações mineiras.

\section{Busca, gerenciamento e fornecimento de recursos energéticos}

Combustíveis fósseis sempre foram um dos principais alvos das atividades dos geocientistas e profissionais da Geologia. O petróleo e o gás natural têm reservas limitadas, que deverão esgotar-se em três ou quatro séculos, se sua utilização continuar no ritmo presente, o qual poderá aumentar acompanhando o crescimento populacional. Carvão mineral ainda poderá ser utilizado por mais tempo, mas, de qualquer forma, trata-se de recurso não-renovável. Em ambos os casos, a queima de combustíveis fósseis é um dos maiores problemas de poluição da atmosfera, por grandes emissões de gás carbônico, possivelmente o componente principal do efeito estufa. A energia nuclear, alternativa utilizada intensamente em certos países, como a França ou o Japão, apresenta o grave problema, ainda não resolvido, da localização dos rejeitos radioativos, cuja solução cabe aos geocientistas. 


\section{Conservação e gerenciamento dos recursos hídricos}

Água potável será o bem natural mais precioso para a humanidade, em futuro próximo. Cabe aos geocientistas o estudo e o gerenciamento da água subterrânea, cuja quantidade no planeta, muito maior do que a água de superfície, permite certa tranqüilidade quanto à disponibilidade futura do recurso. Por outro lado, se a água de superfície é constantemente renovada pelo ciclo hídrico, o que permite a restauração de sua qualidade, caso seja necessário e se existirem os recursos disponíveis, os aqüíferos são muito vulneráveis à poluição, e sua recuperação é extremamente difícil, e mesmo impossível na maioria dos casos.

\section{Conservação e gerenciamento dos solos agricolas}

Solos aráveis, produto final da alteração intempérica das rochas, levam muitos milhares de anos para serem formados. Os solos ideais possuem bom suprimento de nutrientes, estrutura e mineralogia adequadas para a retenção de água e hospedagem de microorganismos, bem como espessura necessária para suportar vários tipos de vida vegetal. Por outro lado, em terrenos utilizados exaustivamente na agricultura, muito material é perdido por diversos fatores, entre os quais a salinização devida à irrigação malfeita, a toxificação pelo uso incorreto de fertilizantes e pesticidas, e a erosão devida ao manejo inadequado, como cultivo em declives, desflorestamento, atividades extrativas. Estimativas recentes dão conta da perda anual de cinco a sete milhões de hectares que vão parar nos oceanos, sem reposição possível: solos também têm que ser considerados recursos não-renováveis, sendo de grande importância a sua conservação e adequada utilização.

\section{Redução de desastres naturais}

Outra importante missão dos geocientistas é o conhecimento, o mais completo possível, dos fenômenos naturais que podem provocar grandes catástrofes como terremotos, erupções vulcânicas, ciclones tropicais, inundações, escorregamentos de terra, secas prolongadas etc. Tais desastres naturais, além de provocarem grandes perdas de vidas e de propriedades, podem ocasionar também atrasos na evolução do desenvolvimento econômico, especialmente para os países do Terceiro Mundo. Cabe às ciências da Terra a tarefa de fornecer os instrumentos para a prevenção de tais desastres naturais e a preparação das comunidades para reduzir a sua vulnerabilidade.

As geociências já possuem a perspectiva global de nosso planeta como um Sistema Terra. As ciências atmosféricas já atuavam em tal perspectiva há muito tempo, e as ciências da Terra sólida (Geologia e Geofísica) tiveram a sua revolução científica - da Tectônica global - há mais de duas décadas. Isto condicionou as tendências, que persistem atualmente, de maior quantificação e de maior 
interdisciplinaridade (Cordani, 1991). A quantificação é cada vez mais visível pela utilização crescente de técnicas tais como sensoriamento remoto, cartografia digital, sistemas de informação geográfica (GIS), bem como interpretações baseadas em complexas simulações e exercícios de modelagem. A interdisciplinaridade decorreu do exame de situações em que se fazia necessária uma visão global, holística, condicionando a participação de elementos com formações diferentes, de todos os campos das Geociências, mas também da Biologia, da Química, da Engenharia etc. (Fyfe, 1994).

Em conclusão, os elementos e a estrutura básica para o conhecimento do funcionamento da Terra já estão em sua maior parte disponíveis. Entendo ser através da cooperação de diferentes especialistas, de muitos campos técnico-científicos, que poderão resultar as soluções adequadas para superar ou contornar as dificuldades propostas pelos desafios ambientais, condições indispensáveis para aproximarmo-nos de uma situação futura de sustentabilidade do planeta.

\section{Os efeitos da mundialização \\ nas sociedades modernas}

De início, partimos da premissa de que um processo de globalização, ou de mundialização, está ocorrendo nesta fase da história, transformando as sociedades nacionais, afetando pessoas, grupos, classes sociais, regiões, países, nações e tendendo para uma sociedade global (Ianni, 1994; Ortiz, 1994).

Tal processo impõe uma transformação epistemológica fundamental para as ciências sociais, em que o seu paradigma clássico, baseado nas sociedades nacionais, está sendo substituído por um paradigma emergente, baseado na reflexão sobre a sociedade global. A globalização implica intensificação das relações sociais em escala mundial, associando localidades distantes de tal maneira que acontecimentos locais sejam influenciados por eventos que podem ocorrer em qualquer lugar do mundo.

A globalização recoloca em discussão muitos dos conceitos das ciências políticas. Por exemplo, devem ser reformuladas as noções de soberania e hegemonia, associadas aos Estados-nação como centros de poder. Na nova ordem mundial, sob a égide da economia capitalista neoliberal, operam novas forças sociais, econômicas e políticas, em escala mundial, que desafiam e reduzem os espaços dos Estados-nação, mesmo daqueles de maior expressão política, anulando ou obrigando reformulações profundas em seus projetos nacionais. As nações buscam proteger-se formando blocos geopolíticos, no interior dos quais cedem parte de sua autodeterminação, e também fazendo acordos sob os auspícios de organizações internacionais (ONU, FMI, GATT etc.), sujeitando-se às suas normas e conveniências temporais. Ao mesmo tempo, surgem novos centros de poder que agem em escalas local, regional, continental e mundial, e dispõem de 
condições para se impor aos diferentes regimes políticos através de suas redes e alianças, de seus planejamentos detalhados e da facilidade em tomar decisões instantâneas em virtude do fluxo de informações que lhes são disponíveis: são grandes empresas multinacionais e conglomerados transnacionais.

As multinacionais normalmente possuem recursos humanos entre os melhores de cada especialidade, os mais avançados recursos tecnológicos e sistemas de comunicação instantâneos, o que lhes permite controlar, na esfera de seus interesses, a produção e o comércio de bens e boa parte das finanças internacionais. Dispõem elas de mais recursos financeiros do que a maioria dos bancos centrais até mesmo de muitos países desenvolvidos e, desta forma, podem especular contra a estabilidade de várias moedas nacionais. Ao mesmo tempo, os Estados enfraquecidos perdem sua capacidade de controlar o fluxo de capitais ao mesmo tempo que diminui a sua capacidade de gerar recursos através de taxas e impostos. Portanto, tais países têm reduzida sua capacidade para investimentos públicos ou para orientar adequadamente os investimentos privados, no sentido de atender com prioridade os segmentos mais pobres de suas populações.

O projeto político neoliberal vigente privilegiando o livre comércio - com redução ou abolição de tarifas alfandegárias - e induzindo a retração dos Estados das funções de produção e planejamento - através das privatizações - é a única opção hoje existente no mundo globalizado. Por outro lado, não está conseguindo reduzir a pobreza no mundo. Até mesmo no país economicamente mais forte, os Estados Unidos, aumenta a desigualdade entre ricos e pobres, e também a proporção destes na população. Mais ainda, a economia neoliberal não conseguiu fazer com que o crescimento econômico em qualquer país, por mais desenvolvido que seja, favoreça a diminuição da taxa de desemprego.

O aumento da riqueza sob controle de grupos privados é o melhor indicador da mudança de poder advinda com a globalização. Não se trata apenas de empresas multinacionais, mas também de outros atores maiores, como os grandes fundos de investimento, fundos de pensão ou similares, sediados em países desenvolvidos, mas que operam em qualquer lugar do mundo. Trata-se de investimentos especulativos, os tais capitais voláteis, que se movimentam rapidamente em transações controladas por redes eletrônicas, ignorando territórios e fronteiras nacionais, sem qualquer possibilidade de controle por parte dos Estados ou das organizações internacionais do setor. Por decisões espontâneas dos grandes investidores, economias nacionais podem sofrer grandes dificuldades, como ocorreu no caso recente do México, refletindo-se em todas as economias dos países latino-americanos, inclusive a do Brasil.

Entendo que a globalização da economia, que atende especialmente aos interesses das transnacionais e dos grandes investidores, acaba pressionando os governos, que de qualquer forma têm de estar inseridos na economia mundial, 
a estabelecer normas e leis nacionais segundo o ideário neoliberal. Dessa forma, surgem medidas como eliminação de tarifas alfandegárias, liberação do fluxo de capitais, privatização dos serviços públicos etc. que, por vezes, podem ser contrárias aos interesses públicos de determinada sociedade civil. Torna-se, portanto, difícil colocar em prática determinadas políticas públicas, determinadas estratégias alternativas de desenvolvimento regional ou nacional baseadas, por exemplo, em princípios social-democratas. A meu ver, este talvez seja o maior problema com que se defronta o novo governo brasileiro.

Pelo exposto, a globalização da economia representa um retrocesso com relação ao caminho que a humanidade tem de seguir em direção à sustentabilidade do planeta. Falamos da necessidade de um acordo social, segundo princípios éticos de solidariedade humana. Evidentemente, encontramo-nos muito longe de tal caminho, pois os paradigmas atuais são aqueles da sociedade de consumo, com seus desperdícios, e suas injustiças sociais.

Se os Estados estão perdendo a capacidade de planejar e de coordenar seus próprios processos de desenvolvimento, quem pode substituí-los no novo contexto da mundialização? É possível imaginar que os mercados livres possam ser capazes de promover o desenvolvimento econômico no mundo todo e, ao mesmo tempo, tomar conta dos aspectos sociais no sentido de atingir a tal sociedade sustentável já caracterizada anteriormente?

No momento, não acredito que existam respostas satisfatórias para tais perguntas. Mais ainda, entendo que a mundialização seja um fato irreversível e a dicotomia Estado versus mercado um falso dilema. A dificuldade real corresponde àquela atualmente enfrentada pelo governo brasileiro, ou seja, como é possível compatibilizar e racionalizar a influência do Estado, sem entrar em choque com as forças da globalização? Como induzir sentimentos de solidariedade e de responsabilidade comum nos diversos segmentos com poder econômico, para que eles contribuam espontaneamente para o processo de desenvolvimento sacrificando, se for o caso, alguns de seus objetivos restritos para o alcance do bem-estar comum da sociedade? É viável pensar-se um governo supranacional, um governo global?

De início, cabe dizer que mundialização não significa homogeneização, similaridade, igualdade. Entendo que a emergência de uma sociedade global, à medida em que esta debilita os Estados-nação, faz ressurgirem movimentos de nacionalismo, regionalismo, com base em culturas e tradições por vezes milenares, que permaneciam em estado letárgico. Por exemplo, mais de 70 anos de domínio por um governo centralizado e potente não foram suficientes para apagar a identidade das muitas nações e etnias que faziam e fazem parte da Rússia, hoje ela mesma remanescente do que foi a União Soviética, tendo de encarar fortes movimentos separatistas, como os que ocorrem na Ossétia ou na Tchetchênia. 
Com a mundialização, ocorre reformulação nas condições de soberania e de hegemonia. A Organização das Nações Unidas poderia ser o embrião de um poder político central, mundial (Ianni, 1992). Entretanto, com seus 50 anos de vida, ela continua sendo muito mais uma promessa. Com suas diversas ramificações, vem se constituindo em espaço para discussões intermináveis, além de centro de decisões tímidas e ações burocratizadas, de pouca eficácia e praticidade. Por exemplo, após diversos anos de preparação, suas decisões nas temáticas de ambiente e desenvolvimento foram consignadas na Agenda 21, documento de síntese, repleto de princípios e de compromissos, aprovado e assinado por todas as nações presentes na conferência do Rio. Após cerca de três anos da Rio-92, quais são as ações realmente relevantes com relação aos compromissos da Agenda 21? Na verdade, parece-me que o diálogo Norte-Sul, que teve seu ponto alto na Rio-92, encontra-se atualmente no limbo, atropelado que foi por outros assuntos considerados de maior prioridade nas agendas das reuniões da ONU.

Acresce que as organizações internacionais existentes, mais ou menos dependentes ou associadas à ONU, acabam priorizando os interesses das nações com maior poder de influência. No caso, é muito comum ver as determinações de organismos como o Banco Mundial, o FMI, o GATT etc. seguirem os princípios ditados pela única superpotência remanescente, os EUA, com uma agravante: os interesses dos Estados Unidos seguem as políticas transitórias de seus governantes, por sua vez condicionados por assuntos internos e interesses menores, muitas vezes antagônicos aos interesses mundiais.

Para mim, não há como visualizar a construção de qualquer estrutura de poder com hegemonia mundial, a curto prazo. Concordo inteiramente com as palavras de Octávio Ianni (1992), quando conclui o capítulo As formas do poder global de seu livro $A$ sociedade global: "Somente no âmbito de uma sociedade global aberta, uma espécie de sociedade civil global, isenta das estruturas de dominação que garantem a alienação de muitos por alguns, somente nessa sociedade pode nascer o cidadão do mundo. Neste caso, a cidadania traz consigo a soberania, traduzindo a essência da hegemonia".

\section{Ambiente, mundialização e economia mineral}

A nova ordem mundial já provocou grandes transformações na atuação de todos os setores das atividades humanas, inclusive e especialmente no das ciências da Terra. A questão ambiental, que assumiu importância crescente em todas as sociedades, obrigou os cientistas e profissionais das ciências da Terra a uma mudança em seu perfil de atividades. Com efeito, em quase todos os países que conheço, desenvolvidos ou não, as organizações principais do setor, os serviços geológicos ou entidades congêneres, já efetuaram reformulações estruturais profundas, criando departamentos ou estruturas análogas para atuarem em atividades ambientais, 
condição necessária imposta pelas respectivas sociedades, até mesmo para garantir sua própria sobrevivência institucional. Dessa forma, os serviços geológicos, em toda parte, preocupam-se menos com mapeamentos geológicos de rotina e mais com operações ligadas a recursos hídricos, geologia de engenharia e recursos minerais.

No caso do gerenciamento dos recursos minerais, já foi mencionada a crise da mineração dos anos 80 , a maior de todos os tempos, afetando principalmente os países desenvolvidos em decorrência das novas demandas sociais que impuseram uma legislação ambiental severa. Esses países estão atualmente empenhados em recuperar o ambiente, em seus respectivos territórios, e implantar condições para mantê-lo limpo. À vista dos encargos que consideraram excessivamente onerosos, as empresas e os investidores do setor mineral têm buscado países que lhes possam oferecer melhor combinação entre potencial mineral e arcabouço institucional. Por exemplo, por causa das rigorosas exigências legais existentes no Canadá e dos possíveis riscos que ocorrem em operações mineiras com relação aos terrenos adjacentes, foram fechadas praticamente todas as minas de cobre que se encontravam em plena operação há alguns anos, apesar da boa qualidade e das reservas importantes do minério. As empresas, canadenses ou multinacionais, foram praticamente todas para o Chile, onde se instalaram com custos operacionais menores.

Neste movimento centrífugo, os capitais de investimento na mineração buscam os países do Terceiro Mundo com evidente potencial mineiro, com certa estabilidade social e com estruturas implantadas que lhes possam oferecer as melhores condições de ganhos financeiros. Entendo que tal tendência poderá persistir por diversos anos e o Brasil se beneficiar dos investimentos estrangeiros no setor, se conseguir efetuar as reformas pretendidas pelo governo na Constituição (BRASIL-DNPM, 1994). Entendo que esta situação poderá ser benéfica para os países em desenvolvimento, visto não serem necessariamente poluidoras as operações de mineração. Com efeito, as minas normalmente ocupam espaço geográfico restrito e as atividades são temporárias, enquanto o minério vai sendo removido. Além disso, as modernas companhias de mineração trabalham com tecnologias ambientais adequadas, de modo que o aproveitamento do bem mineral se faz em bases ecologicamente sustentadas, e a terra pode ser inteiramente reabilitada após a extração do minério, sem perda da qualidade ambiental.

Qual é o futuro da mineração, numa sociedade sustentável, em nível mundial? Recursos minerais serão necessários, em qualquer época, mesmo com o aumento previsível da reciclagem industrial e do aparecimento de novos materiais sintéticos. Com a questão ambiental tendo o mesmo nível de importância, no mundo todo, o desafio será o de encontrar as melhores situações geológicas possíveis e as melhores tecnologias de extração dos minérios. O planejamento e a escolha dos sítios para a realização das operações, porém, deverão ser globais. 


\section{Um novo papel para as Ciências da Terra}

No conhecimento global do planeta, as Ciências da Terra ocupam posição central e integradora, pois fornecem os elementos factuais a respeito de sua superfície, de seus ambientes, relevo, solos, águas territoriais, climas, e processos naturais que nele se inserem em decorrência de sua dinâmica. A ação antrópica sobre o meio físico é intensa e cresce no tempo, acompanhando a expansão populacional. Estima-se que cada indivíduo deste planeta industrializado utilize anualmente entre 10 e 12 toneladas de matérias-primas minerais, 800 metros cúbicos de água e 1.5 quilowatts de energia, produzindo rejeitos da ordem de uma tonelada por ano.

Tais números, já enormes, têm de ser multiplicados por 5.5 bilhões de pessoas! O homem tornou-se um fator geológico dos maiores, e o fluxo de material que movimenta na superfície do planeta é da ordem de grandeza daquele resultante da somatória de processos naturais da dinâmica da Terra (Skinner, 1989).

Como será a situação com 11 bilhões de indivíduos sobre a Terra?

Para mim está claro que, tanto no presente como no futuro, torna-se cada vez mais crítico o planejamento correto do desenvolvimento para evitar decisões ambientais equivocadas, com efeitos desastrosos a longo prazo. Em muitos casos, para decisões capitais sobre grandes projetos integrados envolvendo regiões complexas e ecossistemas pouco conhecidos, os fatos são pouco precisos, os valores discutíveis, os riscos altos, enquanto que a necessidade de tomada de decisão é urgente. Em tais casos, que estão se tornando cada vez mais comuns, o enfoque interdisciplinar é essencial e a participação de diferentes cientistas e profissionais das Geociências absolutamente necessária.

Nossa visão deve tornar-se holística, o mais possível, pois todos os processos que ocorrem sobre a Terra estão interligados. Entendo que para o planejamento de qualquer sistema maior, seja de suprimento de água, de energia ou de minério, deve ocorrer necessariamente a integração do conhecimento e da experiência de muitas áreas da Ciência e da Tecnologia, de geocientistas, engenheiros, economistas, cientistas sociais etc., para evitar grandes equívocos. Por exemplo, ao se construírem represas e açudes, como ocorre no Nordeste do Brasil, visando a favorecer a agricultura, perturba-se o sistema normal de descarga continental pelos rios, que deixam de limpar os ecossistemas terrestres, não levando sais em solução para o oceano. Com a retenção da água e a conseqüente evaporação exacerbada, salinizam-se os solos. Outro exemplo refere-se à construção de enormes hidroelétricas na região amazônica, que pouco acrescentam para as necessidades energéticas brasileiras; entretanto regiões inteiras de floresta tropical são sacrificadas, com perda total da madeira, de valor ignorado, e da biodiversidade na região inundada. 
Finalmente, as organizações científicas têm que tornar-se proativas e não apenas reativas, em proporcionar as equipes consultoras necessárias e em desenvolver as tecnologias apropriadas. Se são os cientistas e profissionais das Ciências da Terra os que possuem o conhecimento principal a respeito de muitos dos problemas que afligem o plantea, são eles que têm a responsabilidade de fazer chegar aos detentores de poder, aos legisladores, aos educadores e também ao público em geral, a sua visão e suas possíveis propostas para enfrentar os desafios relacionados com os processos terrestres.

\section{Considerações finais}

Nos itens precedentes, foram caracterizadas as duas principais dificuldades que, a meu ver, ainda nos deixam muito distantes da sociedade sustentável do futuro. A primeira delas refere-se ao crescimento populacional, o qual vai ainda continuar por muito tempo. Para a sua contenção, será previamente necessária a solução de dois outros grandes problemas: o de adequada educação para toda a população mundial, e o da erradicação da pobreza, em toda parte. A segunda dificuldade diz respeito à perversidade do sistema econômico atual, claramente injusto e não-sustentável, para cuja eliminação se faz necessário o mencionado contrato social, pelo qual a população dos países desenvolvidos deverá desistir de determinados confortos de que presentemente usufrui, enquanto os países em desenvolvimento deverão buscar satisfazer todas as necessidades básicas de suas populações, sem pretender atingir os padrões existenciais das atuais sociedades de consumo.

Mesmo que os indicadores atuais não sejam os mais promissores, seria lícito pensar que podem ser modificadas e invertidas as presentes tendências de explosão populacional e de aumento contínuo das distâncias que separam os países do Primeiro e do Terceiro mundos?

Seria viável sonhar com uma condição futura para a Terra, na qual os seres humanos possam viver em harmonia com a natureza, preservando o ambiente para as gerações futuras?

Algumas décadas seriam suficientes para aproximarmo-nos de tal situação ideal, do novo paradigma?

Nesta altura, a bola de cristal não está clara. Por hipótese, tomo como certeza não haver outra saída possível para a humanidade e, por isso, concluo que a razão deverá prevalecer no sentido de buscar o tal acordo social várias vezes referido.

Para encerrar, repito aqui a mensagem final que dirigi aos geólogos do mundo inteiro, em meu discurso de abertura no $28^{\circ}$ Congresso Geológico Internacional, realizado em Washington, em 1989, que continua oportuna (Cordani, 1989): 
"Francis Bacon in the 17th century wrote, 'Nature to be commanded, must be obeyed'. We live in a challenging world with many uncertainties, and we hold a great responsibility for future generations. We must keep faith in our capacity and remain organized to accomplish our goals, and we must make use of the tremendous potential of international collaboration. Let us start right now to respond to the signals that nature is sending us. Let us obey in order to command again".

Referências bibliográficas

BRASIL - Departamento Nacional de Produção Mineral. Plano plurianual para o desenvolvimento do setor mineral. Brasília, 1994.

CORDANI, U.G. A geologia do futuro. XIV Simpósio de Geologia do Nordeste, 1991. Atas. Sociedade Brasileira de Geologia, NE, Bol. n. 12, p. 9-12, 1991.

Nature to be commanded... Episodes, v. 12, n. 3, 1989.

FYFE, W.S. The role of Earth sciences in society. Paris, Unesco, Nature and resources, v.30, n. 3/4, p. 4-7, 1994.

IANNI, O. A sociedade global. Rio de Janeiro, Civilização Brasileira, 1992.

Globalização: novo paradigma das ciências sociais. São Paulo, IEA-USP, Estudos Avançados, v. 8, n. 21, p. 147-163, 1994.

ORTIZ, R. Mundialização e cultura. São Paulo, Brasiliense, 1994.

SKINNER, B. Resources in the 21 st century: can supplies meet needs? Episodes, v. 12, n. 4 , p. 267-275, 1989.

UNITED NATIONS Fund for Population Activities. The state of the World population, 1991.

WORLD COMMISSION on Environment and Development. Our common future. Oxford, Oxford University Press, 1987.

Resumo

De acordo com os princípios da Agenda 21, o principal documento resultante da UNCED92 , a sociedade sustentável do futuro deverá mostrar um desenvolvimento econômico equilibrado, no mundo todo, em harmonia com os sistemas de suporte da vida, em nosso planeta. As Ciências da Terra têm um papel crucial, visto que elas têm a responsabilidade da busca e do gerenciamento dos recursos minerais e energéticos, da conservação, do gerenciamento dos solos e da água, do monitoramento contínuo dos processos dinâmicos do Sistema Terra e da prevenção e mitigação dos desastres naturais.

Solidariedade social em nível global é necessária para o alcance futuro de uma sociedade sustentável realmente equitativa e preocupada com a justiça social. Entretanto, as 
tendências atuais da globalização, sob a égide dos grandes conglomerados transnacionais, são as de dar menor prioridade face a assuntos como preservação ambiental e desenvolvimento econômico do Terceiro Mundo. Tais tendências precisam ser invertidas, e os cientistas e profissionais das Ciências da Terra devem tornar-se proativos, em comunicarse com políticos, educadores e o público em geral, no sentido de planejar adequadamente as atividades de desenvolvimento, evitando possíveis impactos desastrosos para o ambiente.

\section{Abstract}

Following the principles contained in the Agenda 21, the main agreement reached during the UNCED-92, the future sustainable society shall exhibit an equitable socio-economic development, all over the world, in harmony with the life support systems of our planet. The Earth sciences have a crucial role, because they have the responsibility of the search, provision and management of mineral and energetic resources, the conservation and management of soils and water, the continuous monitoring of the dynamic processes of the Earth system, and the prevention and mitigation of natural disasters.

Solidarity among people is needed in order to achieve a truly equitable sustainable society, worried with social justice. However, the current trends of economic globalization, commanded mainly by transnational business corporations, give low priorities to issues such as environmental preservation, as well as socio-economic development of Third World countries. Such trends shall be reversed, and Earth scientists and professionals shall become proactive in instructing politicians, educators, and the general public, in the wise planning of the development activities, in order to avoid crucial mistakes for the environment.

Umberto G. Cordani é diretor do Instituto de Estudos Avançados da USP, professor do Instituto de Geociências da USP, membro do Comitê Geral do ICSU (Conselho Internacional de Uniões Científicas) e ex-Presidente da IUGS (União Internacional de Ciências Geológicas). Eescreveu mais de 180 trabalhos científicos (artigos, capítulos de livros etc.) em publicações no Brasil e no exterior.

Palestra feita pelo autor em 18 de abril de 1995 no IEA-USP. 